\title{
ARTICLE
}

\section{On Antithiamine Factors of Fern ${ }^{1}$}

\author{
J. C. SomogYI ${ }^{2}$ \\ Institute for Nutrition Research, Rüschlikon-Zürich, Switzerland
}

(Received June 14, 1971)

Before dealing with the actual topic of this paper, it seems important to discuss some concepts in connection with antivitamins so that any misunderstandings will be avoided.

The exact meaning of antivitamins is contradictory. According to the classical definition of Woolley (1) and Shaw (2) an active agent should be considered an antivitamin only when the following terms are fulfilled: 1) similarity of the chemical structure, 2) the symptoms produced by the antivitamin should be similar to those which are caused by lack of the vitamin, 3) the effect of antivitamin should be competitive with the respective vitamin.

However, there exists a number of compounds which are antivitamins but which do not fulfil one or several of these criteria.

It therefore seemed necessary to extend the definition of the antivitamins. Without the extension of the concept, a great number of substances could not be considered as antivitamins, $i . e$. avidine, the antithiamine factors of fern and carp, certain antagonists of pyridoxine, of vitamin D, etc. However, some of them were the very first active agents which were observed to show biological antagonism.

It was proposed therefore some years ago by Somogyi (3) to divide the antimetabolites and naturally the antivitamins into two groups:

A) structurally similar compounds, i.e. antivitamins as they were defined heretofore.

B) structure modifying antivitamins i.e. substances, mainly of biological origin, which destroy or decrease the effect of a vitamin by modifying the molecule itself or building complexes with the vitamin.

The advantage of this classification of antivitamins is that it also allows the distinction which is used for the inhibitors in enzymology. The structurally similar antivitamins correspond to the competitive, and the structure modifying antivitamins to the noncompetitive inhibitors.

Accordingly, an antivitamin may be defined as a compound which diminishes or abolishes the effect of a vitamin in a specific way. One might argue that this is a rather broad definition. It would be difficult, if not altogether impossible, also in this field of biochemistry to offer a definition acceptable to all. This is particularly true since the mechanism of action of many vitamin antagonists is still unknown, making it hard to determine the nature of the reaction taking place.

The application of the proposed new classification of antivitamins in the case of the thiamine antagonists is shown by Fig. 1.

The chemistry and biochemistry of the structurally similar antagonists of thiamine were reviewed in several articles (Woolley (4), Rogers (5), Ariens and Simonis (6) and Somogyi $(3,7))$ and generally speaking, there is little, if any difference in their role and mode of action in different metabolic processes.

In contrast to this, there is considerable disagreement concerning the chemical nature and reaction mechanism of the structure

\footnotetext{
${ }^{1}$ Lecture held at the 200 th Assembly of the Japan Vitamin B Research Committee, 5 th of December 1970 in Kyoto.

2 Address; Prof. Dr. J.C. Somogyi, Institute for Nutrition Research, Seestrasse 72, CH-8803 RüschlikonZürich (Switzerland).
} 


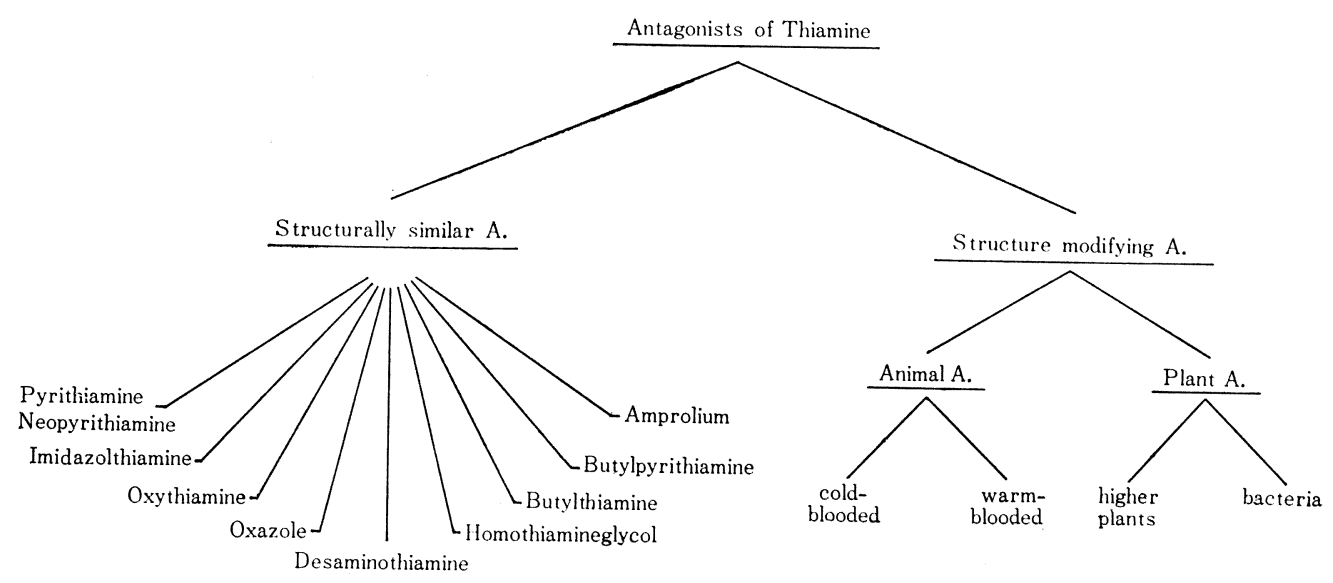

FIG. 1

modifying antithiamine factors.

In my opinion the reason for the disagreement is due to the fact that, with very few exceptions, the active agents had not been isolated in their chemically pure form. This led us to concentrate our efforts of the past years on determining the chemical nature of the structure modifying antithiamine factors in fern and carp viscera, and, if possible, to isolate these factors in their pure state.

The isolation of the active agent of fern was repeatedly attempted, especially by Japanese authors. It is impossible to deal with the extensive literature in such an article, however, I would like to mention that Hasegawa et al. (8) suggested that the thermostable antithiamine factor of fern is a flavonoid. They tested a number of flavonoids, $e . g$. quercetin, isoquercitrin, quercitrin; all have shown an antithiamine activity. Later Sakamoto and Fujita (9) isolated an antithiamine factor from the leaves of sweet potatoes. The yellow needles were identified as isoquercitrin. According to our experiments, they possess only a slight/medium antithiamine activity (Somogyi (10) ).

In the following I shall summarize the results of our own experiments of the antithiamine substances of fern (Pteridium aquilinum) and discuss in this connection the findings of other authors. These experiments were carried out together with my coworkers Dr. Berüter, Dr. Kündig and Dr. Davis, as well as with my late friend Prof. Bönicke.

According to our previous publication, fern contains antithiamine substances. These early experiments have shown that one of the active agents is a thermostable, water-soluble small molecule, which move to the anode in the electric field (Somogyi $(11,12,13))$.

Later a good purification of the antithiamine agent was achieved, although the substance could not be isolated in pure form. This antithiamine factor, called Hydrolysate II, was a red-brown amorphous substance, free of $\mathrm{N}$, P, S and halogens (Somogyi and Koller (14), Somogyi (15), Koller and Somogyi (16)). The specific antithiamine activity of this factor was

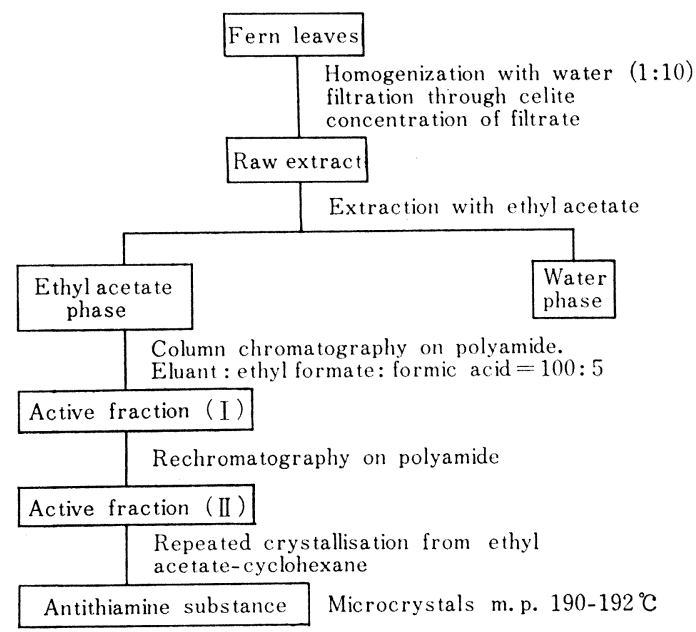

FIG. 2 Scheme of the isolation of a thermostable antithiamine factor of fern. 


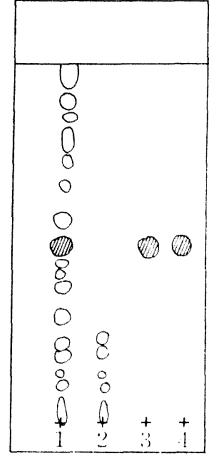

FIG 3. Thin-layer chromatogram of different stages of the purification.

(1) Ethyl acetate phase, (2) water phase, (3) isolated antithiamine substance, (4) 3,4-dihydroxycinnamic acid. Adsorbent: polyamide; developing solvent: ethyl formate: formic acid $=100: 5$; spray reagent: $1 \%$ diphenylboric acid $\beta$-amino ethyl ester in methanol.

confirmed by the experiments with the single nerve fibre of the frog by Petropoulos (17).

These experiments have recently been resumed (Berüter and Somogyi (18)). The antithiamine activity was determined by the thiochrome method and microbiological assay. The purification process, which has been substancially altered, is summarized in Fig. 2.

The antithiamine activity of the darkbrown, oily ethyl acetate phase increased, while the activity of the water phase remained unchanged. The most active fraction of the column chromatography (I) was rechromatographed. The purification effect of the column chromatography has been established by polyamide thin layer chromatograms. Seventeen components could be separated from the ethyl acetate phase (Fig. 3).

One of the components (shaded spot) possessed the highest antithiamine activity $\left(R_{F}=\right.$ 0.47). This could be isolated as a uniform substance.

This compound is a colourless, microcrystalline substance with a melting point 190$192^{\circ}$. Its antithiamine activity is very high, namely $1200 \mu \mathrm{g} / \mathrm{mg}$, according to the thiochrome method (time effect curve) and $1300 \mu \mathrm{g} /$ mg determined microbiologically. The activity is $\mathrm{pH}$ and temperature dependent, being higher in slightly alkaline solutions ( $\mathrm{pH} 7.8)$, than at $\mathrm{pH}$ 6.0.

The substance is thermostable: the antithiamine activity remained unchanged after boiling two hours by reflux. It is soluble in water and ether and easily soluble in ethanol, acetone and ethyl acetate. The microanalyses gave the following results: $\mathrm{C}: 60.83 \% \mathrm{H}$ : $4.57 \%, 0: 33.8 \%$. The molecular weight determined by mass spectrometry was 180 .

The isolated antithiamine compound of fern was identified as 3, 4-dihydroxycinnamic acid (caffeic acid) by the great agreement of the U. V.-, I. R.- and N.M. R.- spectra, the identical behaviour in thin layer chromatography, as well as of the other characteristic properties (melting point, molecular weight, results of the microanalyses).

It was of interest to clarify how other phenol derivatives behaved with respect to antithiamine activity. In this way we hoped to obtain information on the connection between chemical structure and antithiamine effect and possibly insight into the mechanism of action of caffeic acid (Somogyi and Bönicke (19)).

These experiments gave us simultaneously a good opportunity to investigate, whether and how well the determination of thiamine by the thiochrome method and by the microbiological assay agreed with each other.

Thirty-one various phenol compounds were examined. We wanted to clarify which part of the caffeic acid molecule, that is, 1) one $\mathrm{OH}$-group, 2) both $\mathrm{OH}$-groups, 3) the aliphatic side chain, or 4) the entire molecule, is responsible for the antithiamine effect.

The experiments were carried out at $37^{\circ}$ and $\mathrm{pH}$ 7.8. The molecular relationship of thiamine to the investigated phenol derivatives was $1: 3$ in the test mixture. The degree of inactivation of thiamine was measured after 16 hours incubation, in some cases after 24 hours and expressed in percentage of the inactivated thiamine. Thiamine was determined by the thiochrome method as previously described by us $(13,19)$ and microbiologically with L. fermenti (Bönicke (20)). 
TABLE 1

Antithiamine activity of various cinnamic acid derivatives

\begin{tabular}{|c|c|c|c|c|}
\hline \multirow{2}{*}{ Compound } & \multirow{2}{*}{ Structural formula } & \multirow{2}{*}{ MW } & \multicolumn{2}{|c|}{ Inactivated Thiamine } \\
\hline & & & $\begin{array}{l}\text { Thiochrome- } \\
\text { method }\end{array}$ & $\begin{array}{l}\text { Microbiolog. } \\
\text { assay }\end{array}$ \\
\hline & & & \multicolumn{2}{|c|}{ per cent } \\
\hline 3, 4-Dihydroxycinnamic acid & & 180,16 & 98 & 99 \\
\hline Cinnamic acid, $\mathrm{K}$ salt & & 186,24 & 0 & 0 \\
\hline Cinnamic acid, chloride & & 166,61 & 4 & 0 \\
\hline Cinnamic acid, ethyl ester & & 176,22 & 0 & 0 \\
\hline Dihydrocinnamic acid & & 150,18 & 0 & 0 \\
\hline $\begin{array}{l}\text { 3-Methoxy- } 4 \text {-hydroxycinnamic } \\
\text { acid }\end{array}$ & & 194,18 & 0 & 0 \\
\hline Trans- $o$-hydroxycinnamic acid & & 198,18 & 15 & 0 \\
\hline
\end{tabular}

At first, compounds were examined which contained the same side chain as the caffeic acid molecule, but which had no hydroxygroups. The results are summarized in Table 1 .

As is to be seen from this table, those compounds which have no $\mathrm{OH}-$, or only one $\mathrm{OH}$-group, do not inactivate thiamine.

In the next series of experiments, phenol derivatives without the side chain of caffeic acid, but with 1,2 or $3 \mathrm{OH}$-groups in various positions were examined (Table 2).

These experiments clearly indicate, that the number and position of the $\mathrm{OH}$-groups is of primary significance for the antithiamine effect of a phenol derivative.

Catechol, for example, in which compound the two $\mathrm{OH}$-groups are in ortho-position as in caffeic acid, but which lacks the aliphatic side chain, inactivates thiamine practically to the same extent as the 3,4-dihydroxycinnamic acid. Resorcinol, on the other hand, in which the $\mathrm{OH}$-groups are in meta-position, has no activity, while hydroquinone, with two $O H$ groups in para-position, shows a medium antithiamine activity.

These results also support our previous findings, that the aliphatic side chain of caffeic acid plays no role in this effect.

It is interesting to note that compounds, in which the two $\mathrm{OH}$-groups are in orthoposition, but which also have a third hydroxyl goup in the meta-position, as for example py- 
TABLE 2

Antithiamine activity of various hydroxybenzenes

\begin{tabular}{|c|c|c|c|c|}
\hline \multirow[b]{2}{*}{ Compound } & \multirow[b]{2}{*}{ Structural formula } & \multirow[b]{2}{*}{ MW } & \multicolumn{2}{|c|}{ Inactivated Thiamine } \\
\hline & & & $\begin{array}{l}\text { Thiochrome- } \\
\text { method }\end{array}$ & $\begin{array}{c}\text { Microbiolog. } \\
\text { assay }\end{array}$ \\
\hline & & & \multicolumn{2}{|c|}{ per cent } \\
\hline Catechol & & 110,11 & 92 & 92 \\
\hline Phenol & & 94,11 & 0 & 0 \\
\hline Resorcinol & & 110,11 & 9 & 0 \\
\hline Phloroglucinol & & 126,11 & 0 & 0 \\
\hline Pyrogallol & & 126,11 & 28 & 26 \\
\hline Hydroquinone & & 110,11 & 64 & 60 \\
\hline 1,2,4-Trihydroxybenzene & & 126,11 & 29 & 28 \\
\hline
\end{tabular}

rogallol, or in the para-position, as 1,2,4-trihydroxybenzene, show a significantly smaller antithiamine activity.

As the next step, derivatives of benzoic acid were examined, namely those in which the $\mathrm{OH}$-groups are in ortho- and in meta-position. The results of these experiments are summarized in Table 3.

The data of this table indicate that also in this case the antithiamine activity of compounds with the $\mathrm{OH}$-groups in the ortho-position is considerable. On the other hand, those compounds in which the two OH-groups are in meta-position, exert no antithiamine activity.

Finally, the antithiamine effect of derivatives of catechol and tyrosine was determined.
The results are contained in Table 4 .

All of the examined catechol derivatives, in which the $\mathrm{OH}$-groups are in ortho-position, possess-with the exception of adrenaline-a high antithiamine activity. Also chlorogenic acid, an ester of caffeic acid, shows a significant antithiamine effect. On the other hand, thiamine is not inactivated by compounds in which the aliphatic side chain of caffeic acid is substituted by $\mathrm{OH}, \mathrm{CHO}$, or $\mathrm{NO}_{2}$, even when the two $\mathrm{OH}$-groups are in the ortho-position, as for example in 4-nitrocatechol or 3,4-dihydroxybenzaldehyde.

A possible explanation for this observation may be, that these compounds, under the test conditions mentioned, do not exist as the dihy- 
TABLE 3

Antithiamine activity of various benzoic acid derivatives

\begin{tabular}{|c|c|c|c|c|}
\hline \multirow{2}{*}{ Compound } & \multirow{2}{*}{ Structural formula } & \multirow[b]{2}{*}{ MW } & \multicolumn{2}{|c|}{ Inactivated Thiamine } \\
\hline & & & $\begin{array}{l}\text { Thiochrome- } \\
\text { method }\end{array}$ & $\begin{array}{l}\text { Microbiolog. } \\
\text { assay }\end{array}$ \\
\hline & & & \multicolumn{2}{|c|}{ per cent } \\
\hline 3, 4-Dihydroxybenzoic acid & & 172,14 & 80 & 85 \\
\hline 3, 4, 5-Trihydroxybenzoic acid & & 188,14 & 73 & 70 \\
\hline $\begin{array}{l}3,5 \text {-Dimethoxy-4-hydroxyben- } \\
\text { zoic acid }\end{array}$ & $\mathrm{H}_{3}$ & 198,18 & 28 & 17 \\
\hline $\begin{array}{l}3,4,5 \text {-Trihydroxybenzoic } \\
\text { acid ethyl ester }\end{array}$ & & 198,18 & 71 & 60 \\
\hline 2, 4-Dihydroxybenzoic acid & & 154,13 & 0 & 0 \\
\hline 3,5-Dihydroxybenzoic acid & & 154,13 & 0 & 0 \\
\hline
\end{tabular}

droaromate, but as a hydroxyphenolate, i.e. one of the $\mathrm{OH}$-groups is dissociated to $\stackrel{(-)}{\mathrm{O}}$. This assumption has been verified by the results of the determination of the $\mathrm{pK}$ values of the examined substances. ${ }^{2}$

From these series of experiments one can conclude, that among the phenol derivatives examined, there exists a close connection between the chemical structure and the antithiamine effect.

Hasegawa et al. (8) found also that phenolic compounds possess an antithiamine activity. However, they did not find the same close connection between chemical structure and antithiamine activity of various phenol derivatives as we. According to their experi- ments, phenols with one $\mathrm{OH}$-group possess also a certain antithiamine effect, in our investigation-as mentioned above-they did not show any activity. On the other hand, triphenols, e.g. 3, 4, 5-trihydroxybenzoic acid and its ethylester have shown in our experiment in contrast to those of Hasegawa a marked activity. Both groups of investigators found, however, that ortho-diphenols inactivate thiamine to a great extent.

Further it was also established by these experiments that in the determination of thiamine a very good agreement exists between the thiochrome method and the microbiological assay.

In this connection it was of interest to

${ }^{2}$ The $\mathrm{pK}$ determinations were carried out by Prof. Dr. W. Simon of the Institute of Organic Chemistry of the Swiss Federal Institute of Technology, Zürich. 
TABLE 4

Antithiamine activity of various catechol derivatives and of tyrosine

\begin{tabular}{|c|c|c|c|c|}
\hline \multirow{2}{*}{ Compound } & \multirow{2}{*}{ Structural formula } & \multirow{2}{*}{ MW } & \multicolumn{2}{|c|}{ Inactivated Thiamine } \\
\hline & & & $\begin{array}{l}\text { Thiochrome- } \\
\text { method }\end{array}$ & $\begin{array}{c}\text { Microbiolog. } \\
\text { assay }\end{array}$ \\
\hline & & & \multicolumn{2}{|c|}{ per cent } \\
\hline 4-Methyl catechol & & 124,14 & 98 & 94 \\
\hline DL-Dioxyphenylalanine & & 197 & 95 & 99 \\
\hline $\begin{array}{l}\text { 3-Hydroxytyramine hydro- } \\
\text { chloride }\end{array}$ & & 180,65 & 97 & 97 \\
\hline Adrenaline & & 183,21 & 56 & 69 \\
\hline Chlorogenic acid & & 354,32 & 95 & 96 \\
\hline $\begin{array}{l}3,4 \text {-Dihydroxyphenylacetic } \\
\text { acid }\end{array}$ & & 168 & 97 & 96 \\
\hline 3, 4-Dihydroxybenzaldehyde & & 138,13 & 18 & 0 \\
\hline 4-Nitrocatechol & & 155 & 0 & 0 \\
\hline Tyrosine & & 181 & 0 & 1 \\
\hline
\end{tabular}

clear up the following two questions: 1) the influence of heavy metals, e.g. $\mathrm{Cu}^{2+}$ and $\mathrm{Fe}^{2+}$ on the inactivation of thiamine by orthodiphenols, 2) the kind of this reaction i.e. whether it is of aerobic or anaerobic nature.

The effect of $\mathrm{Cu}^{2+}\left(\mathrm{CuSO}_{4}\right.$ anhydrous p.a. $)$ and $\mathrm{Fe}^{2+}\left(\mathrm{FeCl}_{2} \cdot 4 \mathrm{H}_{2} \mathrm{O}\right.$ p.a. $)$ was investigated with respect to inactivation of thiamine by caffeic acid at $37^{\circ}, \mathrm{pH} 7.8$ and after a reaction time of 16 hours. The reaction mixtures were kept in the dark during the experiment.

These experiments have shown that $\mathrm{CuSO}_{4}$ 
and $\mathrm{FeCl}_{2}$ in a concentration of $1 \mu \mathrm{m}$ and 5 $\mu \mathrm{m}$ do not influence the thiamine inactivation by caffeic acid. $1 \mu \mathrm{m} \mathrm{CuSO}_{4}$ and $1 \mu \mathrm{m} \mathrm{FeCl}_{2}$ also does not inactivate thiamine and at a concentration of $5 \mu \mathrm{m}$ only to a small extent.

These results are very similar to those, which we have recently published. Neither $\mathrm{Cu}$ nor $\mathrm{Fe}$ did affect the inactivation of thiamine by hemin (Somogyi and Kündig (21)).

By further experiments we tried to clear up the reaction mechanism of the inactivation of thiamine by caffeic acid and other orthodiphenols e.g. catechol (Davis and Somogyi (22)). Our initial attempt to examine this mechanism revealed, that the course of reaction was distinctly biphasic (Fig. 4). Besides the marked difference in velocity, the two phases further proved to be different in nature by their dependency on oxygen.

These experiments were made in a Warburg apparatus under atmospheric pressure. The rates of thiamine inactivation by caffeic acid or catechol were compared under aerobic and anaerobic $\left(99.7 \% \mathrm{~N}_{2}\right.$ ) conditions.

The course of reaction in aerobic and anaerobic systems is indicated in Fig. 5. The initial phase shows itself to be independent of oxygen. The second phase is oxygen dependent, however, the availability of oxygen appears not to be the rate limiting factor since there is no increase in velocity when the reactions are run under pure oxygen.

In the course of $\mathrm{pH}$ studies, it was observed that the initial phase was essentially independent of the hydrogen ion concentration

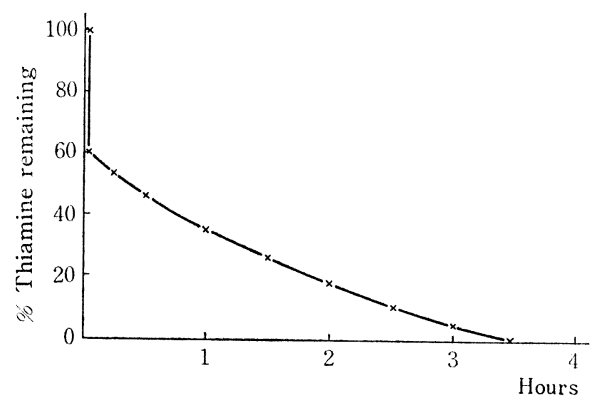

FIG 4. Time course of thiamine inactivation by catechol. $45^{\circ}, \mathrm{pH} 7.5$

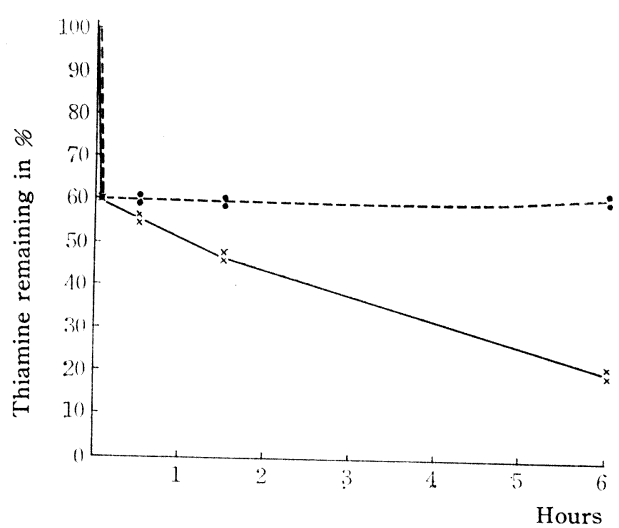

FIG 5. Inactivation of thiamine by caffeic acid under aerobic and anaerobic conditions.

$\times$, aerobic, - - anaerobic. $37^{\circ}, \mathrm{pH} 7.5$

over the examined range of $\mathrm{pH}$ 4.5-7.8. The second phase, however, can take place only above $\mathrm{pH}$ 6.5. This characteristic of the reaction conveniently allows the two phases to be examined independently (Table 5).

Results of the determination of the molecular ratio were variable, from less than $1: 1$ to approximately 4 moles of thiamine inactivated by 1 mole of catechol, depending on the concentration. The greater than $1: 1$ ratio is perhaps due to a recyclization, a characteristic of catechol also seen in its oxidative deamination reaction of amino acids (Trautner and Roberts (23)).

The effect of temperature has further served to differentiate the two phases. The first phase demonstrates an apparent temperature independence, in that it is complete before the first sample can be withdrawn at approximately 7 seconds. The second phase,

TABLE 5

Effect of pH on initial and second phase of thiamine inactivation reaction

\begin{tabular}{ccc}
\hline $\mathrm{pH}$ & $\begin{array}{c}\text { Initial phase } \\
\left.\text { (inact. within } 7^{\prime \prime}\right)\end{array}$ & $\begin{array}{c}\text { Second phase } \\
\text { (inact. between } \\
\text { and 120 }\end{array}$ \\
\hline \multicolumn{3}{c}{ per cent } \\
4.5 & $39 \pm 2$ & 0 \\
5.5 & $40 \pm 2$ & 0 \\
6.5 & $40 \pm 2$ & 11 \\
7.0 & $41 \pm 2$ & 29 \\
7.5 & $40 \pm 2$ & 40 \\
7.8 & $41 \pm 2$ & 51 \\
\hline
\end{tabular}




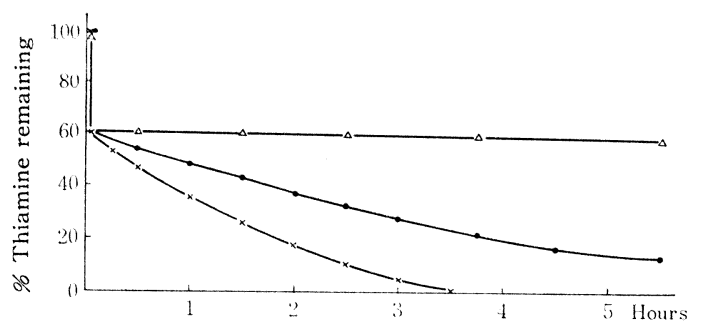

FIG 6. Effect of temperature on inactivation of thiamine by catechol.

$\times-45^{\circ},-137^{\circ}, \cdots-10^{\circ}, \mathrm{pH} 7.5$

on the other hand, is markedly temperature dependent. Using the normal $1: 1$ ratio of reactants, there is essentially no second phase below $20^{\circ}$, where the initial phase exists to its normal extent (Fig. 6). Only an excess of the inactivating diphenol promotes a reaction at this temperature.

The reaction has been observed to be partially reversible by the addition of cysteine (or other reducing substances, such as ascorbic acid) to the assay mixture. As Fig. 7 shows, the extent of reversibility is dependent on the contribution at any time of the initial phase to the reaction, since only this phase is reversible. The second phase, at least under the experimental conditions, is irreversible. The contribution of the first and second phase at any time can thus be determined for kinetic evaluation of the reaction.

This observation was particularly important in view of the above mentioned comparative studies on the amount of thiamine inactivated by various diphenols, as determined chemically and microbiologically (18). Although there was

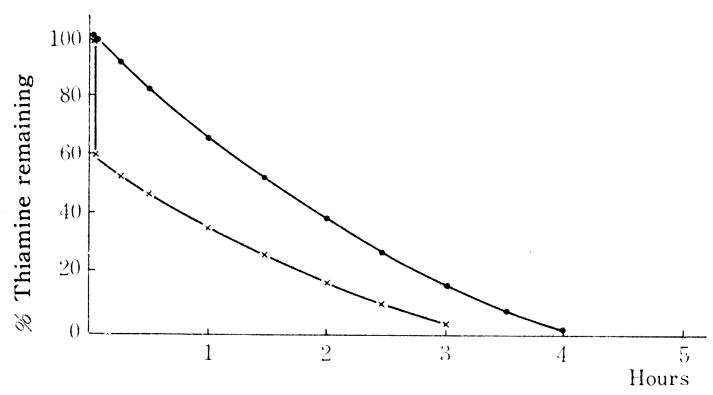

FIG 7. Reversibility of reaction by addition of cysteine to assay mixture.

$-\times-$, without cysteine, - - - with cysteine good agreement in most cases between the two methods, with respect to the total amount of thiamine inactivated, there was a discrepancy in the course of the reaction. By chemical determination the lower curve of the Fig. 7 was obtained, by microbiological assay the upper one. This difference can now be explained as being due to the fact that the chemical method determines only that amount of thiamine which is completely free, while the microbiological assay determines both free thiamine and that which is reversibly bound.

Although thiamine is rendered chemically and microbiologically inactive by the caffeic acid, there is as yet no evidence for an addition product. The observation that one mole of diphenol can inactivate several moles of thiamine, along with the results of chromatographic experiments, would indicate that each reactant is mutually altered in an oxidation-reduction reaction. Column chromatographic separation of the reaction products and determination of the structure of the inactive form of thiamine are in progress.

Finally I would like to mention briefly the results of our recent experiments by which the discrepancy between the findings of the Japanese authors and of my group with regard to the existence of a thermolabile antithiamine factor of fern could be clarified. Our new experiments show that ripe leaves of bracken fern (Pteridium aquilinum), of Adiantum capillus veneris and of Matteucia struthiopteris contain only a thermostable factor, while leaves with spores (Adiantum) or the spores of the variety of Matteucia struthiopteris possess mainly a thermolabile and to a small extent a thermostable factor (Ono and Somogyi (24)).

An attempt has been made to convey information about our investigations on antithiamine substances and to show the solved and unsolved problems in the very interesting field of antithiamines.

\section{REFERENCES}

1. Woolley, D. W., A Study of Antimetabolites. Wiley and Sons, New York (1952). 
2. Shaw, E., Metabolism, 2, 103 (1953).

3. Somogyi, J. C., Metaboliten und Antimetaboliten in, Ergebnisse der Medizinischen Grundlagenforschung, hrsg. von K. F. Bauer; Thieme, Stuttgart, p. 141 (1956).

4. Woolley, D. W., In, Metabolic Inhibitors. R. M. Hochster and J.H. Quastel, eds. Academic Press, New York, p. 445 (1963).

5. Rogers, E. F., Ann. N.Y. Acad. Sci., 98, 412 (1962).

6. Ariens, E. J., and Simonis, A. M., Arch. Int. Pharmacodyn., 139, 60 (1962).

7. Somogyi, J. C., Bibl. "Nutr. et Dieta" 1, 77 (1960) S. Karger, Basel.

8. Hasegawa, E., Sakamoto, S., Nagayama, K. and Fujita, A., J. Vitaminol, 2, 31 (1956).

9. Sakamoto, S., and Fujita, A., J. Vitaminol, 2, 39 (1956).

10. Somogyi, J. C., unpublished results (1957).

11. Somogyi J. C., Int. Z. Vitaminforsch., 21, 341 (1949).

12. Somogyi, J.C., Helv. physiol. Acta, 9, C 79 (1951).
13. Somogyi, J. C., Die Antianeurin-Faktoren. Huber, Bern (1952).

14. Somogyi, J.C., und Koller, A., Internat. $Z$. Vitaminforsch., 29, 234 (1959).

15. Somogyi, J.C., Bibl. "Nutr. et Dieta", 8, 74 (1966). S. Karger, Basel.

16. Koller, A., und Somogyi, J.C., Internat $Z$. Vitaminforsch., 31, 230 (1961).

17. Petropulos, S. F., J. cell. comp. Physiol., 56, 7 (1960).

18. Berüter, J., and Somogyi, J.C., Experientia, 23, 996 (1967).

19. Somogyi, J.C., and Bönicke, R., Internat. Z. Vitaminforsch., 39, 65 (1969).

20. Bönicke, R., unpublished results.

21. Somogyi, J.C., und Kündig, H., Internat. Z. Vitaminforsch., 38, 503 (1968).

22. Davis, J.S., and Somogyi, J.C., Internat. Z. Vitaminforsch., 39, 401 (1969).

23. Trautner, E. M., and Roberts, E. A.H., J. of Scientific Res., Ser. B., 3, 356 (1951).

24. Ono, T., and Somogyi, J.C., in print. 